\title{
Occupational health and safety in New Zealand: problems and solutions
}

\author{
Paul Duignan*
}

An economic climate which promotes cost cutting, lack of resources for regulatory agencies, enforcement bodies which are reticent to enforce, legislation which is uncoordinated and not communicated to those who need it, information which is available in university departments but not on the shop floor, and no effective sanctions in terms of penalties and increased levies against negligent employers all threaten the health and safety of New Zealand workers. These problems are outlined and improvements such as more resources for regulatory bodies, a more positive policing role for enforcement agencies, integration of legislation and administration, better information flow, effective sanctions against employers and particularly more worker involvement in occupational health and safety are proposed.

Just on once every 2 days a New Zealand worker dies from a work accident. Each day it can be expected that at least 3 workers will be permanently disabled and 120 others will be injured to the extent that they will be off work for more than a week. In addition to these industrial accidents, there is the problem of diseases caused by occupation. The extent of this additional problem is hidden for 2 reasons. Firstly, the difficulty of clearly establishing an occupational cause for a disease which may have a range of possible causes; secondly, the long latency period which characterises many of the occupational diseases. It is however clear that the occupational illness problem is at least as significant as that of occupational accidents and the future could well see increasing risks from occupational diseases due to the proliferation in the use of industrial chemicals.

The most facile of all debates in the area of occupational health and safety is whether or not this level of human suffering compares favourably with, first, non-occupational injury and illness and, second, with the occupational accident and illness records of other countries. All that can be said from those international comparisons with New Zealand's record which can be made, is that there is room for improvement. To decide where these improvements need to be made we need to look at the factors which determine the quality of the working environment. These factors include the economic climate which influences the priority accorded to health and safety; the effectiveness of the regulatory agencies; the clarity and comprehensiveness of occupational health and safety legislation; the size of the penalties for breaches of legislation; the amount and quality of information and education on health and safety available; the sanctions against employers in terms of liability cover for occupational injuries; and the trade union response to this problem. I intend to discuss each of these factors in turn and suggest ways in which improvements may be made to our current activity in the field of occupational health and safety in this country.

* Research Officer New Zealand Federation of Labour. 


\section{Economic climate}

It is quite obvious that the current economic recession will influence the priority which is given to measures to improve the working environment. The first line of attack on workplace hazards is always the substitution of safe materials for hazardous substances or processes, followed by the introduction of engineering controls to reduce the level of hazard. Usually, safer alternatives cost more, otherwise they would already be in use. For example, trichloroethylene, a common solvent in industry, is more toxic than some of the other suitable solvents but it is also less expensive and hence continues in wide use. Engineering controls also always cost something and often require a substantial outlay on the part of the company. In conditions of economic stringency, employers are less likely to commit themselves to paying for such controls. Workers, facing the prospect of possible unemployment, are less likely to complain of hazardous conditions and also are unable to move to a safer job if faced with a dirty and dangerous workplace.

Since these economic pressures are working against the improvement of the working environment, it is important that, at this time, other controls on the workplace are improved or at least maintained at their current level. Unfortunately, the same economic pressures which make it more likely for employers to resist taking measures to improve conditions in the workplace and to cut corners in regard to occupational health and safety, are also at work within the regulatory agencies charged with protecting the work invironment; within trade unions attempting to protect their members health and safety; and within universities and other institutions involved in providing research and information on workplace hazards. In addition, times of economic recession are usually characterised by an increased emphasis on a laissez-faire ideology which promotes glib notions such as the call for "deregulation" of industry. This does not create the best of political climates in which to argue for the increased health and safety controls which are particularly needed in these adverse economic times.

\section{Regulatory agencies}

Regulatory agencies such as the Department of Labour and Department of Health are essential in maintaining the standard of the working environment. Both departments are under pressure from cuts in government expenditure. For instance, comments on staff ceiling levels from the 1980 Department of Labour report are as follows:

The Department appreciates the need for close control of public spending. However, it views with some concern, the long-term effects that will inevitably stem from inadequate surveillance on working conditions and forsees a general lowering of the standards affecting the safety, health and welfare of the workforce as a consequence. (Department of Labour, 1980, p. 28)

A review of the factory inspectorate, completed by the Department of Labour and the State Services Commission in 1978, called for the number of factory inspectors to be approximately 315 . At the moment, the factory inspectorate has about 168 inspectors. It is no wonder that the Department of Labour is having problems carrying out its job of inspecting the compliance of industry with the various standards set down in New Zealand's occupational health and safety legislation.

The Department of Health is in a somewhat similar position with the additional problem of being unable to recruit adequately trained personnel. For instance New Zealand, to my knowledge, has only one properly trained occupational hygienist. The occupational hygienist, a person who has specialised in the study of the protection of workers within the work environment is the key health specialist in the protection of the working environment. To have so few suitably trained people in New Zealand is to guarantee a lack of expertise in the protection of the workplace. Occupational medicine, as a speciality within medicine, has not been highly regarded within the medical profession, which reflects, to some extent, the socioeconomic pre-occupations and concerns of our society as a whole and of the 
medical professional specifically. However, those few enthusiasts who do enter the field have shown the impact that can be made in this much neglected area. It is only recently that a diploma in occupational health has been established at a medical school in New Zealand. Prior to that all occupational medicine training had to be undertaken overseas.

In addition to the problems which the various regulatory agencies have in regard to staffing and resources, there is the general problem of a multiplicity of regulatory agencies in the occupational health and safety field. It is currently not clear to a worker or employer which government department should be approached in regard to health and safety problems. The presence of the Accident Compensation Corporation (ACC) on the scene introduces a further element of confusion as to the responsibilities of government and quasi-government agencies in this area. As a first step in the rationalisation of inspectorate and advisory services, a series of clear guidelines need to be prepared which indicate the various responsibilities of these agencies in occupational health and safety.

One of the interesting aspects of the New Zealand health and safety scene is the way in which the various regulatory agencies vie with one another to escape from a policing role in occupational health and safety. ACC indicates that it is only able to advise industry, and that it will not go into a firm unless invited. The Department of Health states that its role is very much an advisory role, and the Department of Labour is the only department which admits, although apologetically, to having a significant enforcing role. It should be noted that of the 43458 breaches of the Machinery Act and the safety, health and welfare provisions of the Factories Act in the year ending 31 March 1982 only 93 prosecutions were taken; resulting in a total of 74 convictions (Department of Labour, 1982, p. 53).

This can be compared, in a limited way, with traffic offence and infringement notices of which 615450 were issued in the same period resulting in 168565 prosecutions and 145985 convictions. The apparent reticence on the part of government and quasi-government agencies to be involved in policing occupational health and safety may be able to be traced in part to the sustained attack on government regulation by private enterprise apologists over the last few years. While the economic determinants of this enthusiasm for the delights of uncontrolled free enterprise are clear, it is unfortunate that the alternative point of view is not being put. It is as essential to have enforcement in regard to occupational health and safety as it is in regard to traffic laws.

In the face of the confusion created by the number of government agencies involved in occupational health and safety, a good case can be made for their integration. Such integration would mean a common approach, easier identification of the agency by the public, and possibly more efficient use of equipment, research and administrative resources. Such an integration, in the long term was proposed in the recent inquiry into health and safety legislation carried out by Dr I.K. Walker for the State Services Commission (Walker, 1981). The last decade has seen an international move towards the integration of government agencies such as in the United Kingdom where the Health and Safety Executive has been established. Whether such an integration would result in a more positive attitude towards enforcement of legislation is debatable. However, no matter what attitude is held towards the question of integration, it is clear that there need to be guidelines established on the responsibilities of the various departments, better co-ordination, more resources, and a more aggressive attitude towards the enforcement of health and safety legislation in this country.

\section{Legislation}

Occupational health and safety legislation in New Zealand is in a state of chaos. Major pieces of legislation which have provisions dealing with the workplace include the following, the Factories and Commercial Premises Act 1981, Machinery Act 1950, Construction Act 1959, Health Act 1956, Bush Workers Act 1945, Poisons Act 1960, Clean Air Act 1972, Radiation Protection Act 1965, Coalmines Act 1979, Mining Act 1971, Petroleum Act 1937, Quarries Act 1944, Boilers, Lifts and Cranes Act 1950, Shipping and 
Seamen Act 1952, Harbour's Act 1950, Electric Linemen Act 1959, Electrical Registration Act 1979, Dangerous Goods Act 1974, Explosives Act 1957, Tramways Act 1908, Agricultural Chemicals Act 1959, and the Toxic Substances Act 1979. In addition to these acts, there are numerous regulations which provide more detailed provisions on occupational health and safety.

This legislation, which has been enacted in the hope that it will protect the working environment, now presents a daunting prospect for enforcement. There are at least 5 government departments charged with administering various parts of this legislation. There are those who argue that what is needed in the area of occupational health and safety is a reduction in the amount of regulation. The attack on the Occupational Safety and Health Administration (OSHA) initiated by the Reagan administration in the United States is an example of this type of philosophy. While some of the "deregulation" lobby simply seek to allow industry a free rein and do not consider workers health as important, there are others who believe that some sort of self-regulation of industry is preferable to statutory regulations. What this latter group of people fail to realise is that there is often a conflict between company profit and outlaying money for health and safety provisions. It is therefore essential that there is an adequate body of properly enforced occupational health and safety regulations to provide protection for workers.

For statutory regulations to be of any use however, they need to be clear and they need to be communicated to employers who have to meet their requirements and to workers so that they can check whether those requirements are being met. An example is useful to illustrate this point. An employer involved in fibreglassing work will have to be familiar with legislation and regulations from the Factories and Commercial Premises Act 1981, the Health Act 1956, the Dangerous Goods Act 1974, in addition to the electrical wiring requirements of the appropriate local body. It is difficult for the employer to get all the information he or she needs in order to meet these legislative requirements. The position is even worse for a worker in the fibreglassing industry. While it is their health which is at risk, they have virtually no way of finding out the legal requirements with which their employer should be complying.

The solution to this problem is clear. What is needed is information material which concisely draws together the various requirements for each area of industry and which can be made available to employers, and through their unions, to the workers who are involved in the industry. In the general area of occupational health and safety legislation there needs to be the publication of a legislative guide such as is available for overseas legislation. For instance, Butterworths have produced a guide to safety and industry laws in New South Wales which outlines the requirements of their occupational health and safety legislation. Such a publication in New Zealand would be most welcome and would go a great way towards providing the type of information which is needed by employers and unions in dealing with occupational health and safety legislation. The question of the provision of more specific information such as that relating to 1 industry only is dealt with in the section on information and education.

\section{Penalties}

The current penalties for employers who breach health and safety regulations and put workers health at risk are fai too low. The absence of significant penalties leads to a breakdown in the safety of the working environment. Without any economic pressure to improve the work environment, it is most unlikely, particularly in times of economic stringency, for money to be outlayed on improvements. The Factories and Commercial Premises Act 1981, provides for fines of up to $\$ 5000$ for those who refuse to allow inspectors into an undertaking, obstruct inspectors, victimise a complainant, stop someone from seeing an inspector, or fail to meet any requirement of an inspector. Continuing offences can result in a fine of up to $\$ 250$ for each day they continue and if an offence results in death of injury then the fine can be increased to $\$ 10000$. 
It is useful to look at the actual fines which are imposed for breaches of the legislation. In one recent instance, a young worker was killed when the abrasive grinding wheel he was using disintegrated and a fragment struck his head. The grinding machine was a converted circular saw bench which was unsuitable for this type of work and the governor on the wheel was not working properly. The firm was fined $\$ 400$ for failing to guard the transmission machinery and the abrasive wheel. In another instance, a large company was fined \$2 000 for failing to securely fence a dangerous part of a machine as required by the Machinery Act 1950. This followed a fatal accident to a worker who, because of the lack of proper guarding, fell into the machine. These amounts of money, for the large employer at least, are unlikely to act as a sanction against taking short cuts which result in hazardous situations. In the demolition industry for example, contractors can often be forced to pay up to $\$ 5000$ for each day demolition work continues after the agreed date of completion of a contract. Companies are unlikely to take any precaution which would slow down their operation because even if workers die as a result of negligence on the part of the company, it is unlikely that they will be fined anywhere near the amounts they are likely to lose by over-running their completion dates.

One major way of solving the problem of it being uneconomic in some circumstances for companies to take health and safety precautions is to simply raise the level of fines which companies have to pay as penalties for negligence. In submissions on the Factories and Commercial Premises Bill, the Federation of Labour proposed fines of up to $\$ 100000$ for some instances of negligence. There needs to be a fear of being fined a substantial amount of money to act as a sanction against those employers who take risks with workers' lives for profit.

\section{Information and education}

One of the most critical factors preventing an improvement in the work environment in New Zealand is the lack of effective channels for the flow of useful information to those faced with health and safety problems and in a position to do something about them. There is a great deal of scientific information available relating to the hazards of the workplace. While there is a need for continuing research in many areas of occupational health and safety, such as in the further identification of occupational causes of disease, there is a most pressing need at this time for the widespread dissemination of existing information to the workplace where it can be applied. For example, at a recent seminar for shop stewards, 1 shop steward, who worked in a foundry, asked if there could be any significance in the fact that a number of his co-workers over the last 10 or so years had developed cataracts. It is well known in the scientific community that infra-red radiation such as that emitted from a furnace can cause cataracts. This information, which could be easily obtained from any of the standard reference works on occupational health and safety, had not been given to the worker. It is unclear as to whether the employer was aware of this information and deliberately withheld it from the workers involved, or that the employer was simply ignorant of the effects of infra-red radiation. The significant point here comes back once again to a question of economics. It is in the economic interest of the employer to obtain a great deal of technical information about the production process which relates to the cost-effectiveness of the process and to its quality control. It is not however in the employer's economic interest to seek out information about occupational health and safety. Such information, as in the case of the foundry workers, would cost the employers something to obtain and something to remedy the hazardous situation. While in this and many other situations it would not involve a great deal of money to solve the problem, it is still highly unlikely that employers will seek out that information which is required for an improvement in the working environment, unless there is a financial pressure to do so.

Throughout the country there are workers who are using chemicals with absolutely no knowledge of their long term health effects. In many instances, even the true name of the 
chemical is kept from them. Even in those instances where some information is available from manufacturers, data sheets may overlook hazards from the chemicals they are describing. A recent example from the United Kingdom was a manufacturers' data sheet for carbon tetrachloride. This sheet failed to note the established fact that this solvent can cause liver injury. Workers, of course, do not have any legal right to know what substances they are using. In fact a standard reply to requests to companies for the constituents of their products is that it is not their policy to divulge product formulations. This protection of "trade secrets" ensures that workers can have no complete knowledge of the substances they are using. As a consequence, workers have no way of checking information from manufacturers where it is available, or of obtaining basic information when, as often happens, it is not available from the manufacturer.

Even when information is made available it is often obscured by the way in which it is presented. Often, 1 name is used for a chemical without any indication of its alternative names. Abbreviations are used without explanation, irrelevent information is included and vital information absent. Clearly, those who write data sheets do not consider carefully enough who is going to use them and what information will be of most value. Part of the problem flows from the attitude of the scientific community. Their inability to report results in clear English has been elevated to the level of an art form. In 1 instance, suggestions from trade union representatives for improvement in the clarity of the New Zealand Threshold Limit Value booklet were met with the comment from one occupational health specialist that, if people could not understand the booklet as it is, then they should not be using it. Undoubtedly, a similar argument was advanced against translating the bible from Latin into English in the Middle Ages.

A further area in which transfer of information is important, is in the area of solutions to occupational hazards. When workers from the same industry are brought together to discuss occupational health and safety, workers at one plant often find that a hazard which has been causing them problems, and for which management has said there is no feasible solution, has been solved for a number of years in the plant of a competing firm which is involved in a similar process. An information collection should be established which provides details of solutions for various problems which arise in the workplace. This data base should incorporate information from overseas experience and be available to employers and unions throughout the country so, that instead of each solution in each plant having to be developed in isolation, there can be a cross-flow of ideas for the general improvement of the working environment.

The provision of education for occupational health and safety is largely a matter of equipping people to be able to seek out the appropriate information which can be used in solving the particular problem they are facing. Such education for employers obviously needs to be linked to economic sanctions forcing them to obtain and use the information which is available. For workers, education on health and safety needs to be linked to the fact that they have a right to information about the hazards they face and that they will only achieve an improvement in the working environment by first bringing problems to the attention of management, and secondly by applying basic trade union principles in putting pressure on management where there is no action by management to remedy a problem.

The information and education problem can be tacked in a number of ways. The first is to create financial incentives for employers to seek out information on occupational health and safety hazards through rigid enforcement of health and safety regulations and significant penalties as outlined in the previous section. In addition to this, however, there needs to be the effective provision of information to employers and to workers about the hazards of the workplace. While it is not usually in the interest of employers to find out information about hazards in the workplace, it is very clearly in the interest of workers to receive such information. A legislative entitlement to know what substances one is working with needs to be backed up by resources being made available for the dissemination of clear informative material about the hazards of the workplace. 


\section{Accident Compensation and common law liability}

The total removal of the common law right to sue, brought about by the Accident Compensation Act 1974 meant a radical change in the basis of New Zealand law in regard to compensation for accident injury. The introduction of the Accident Compensation Act and the removal of the common law right to sue have been described by a United States law journal as "an unparalleled event in our cultural history, the first casualty among the core legal institutions of the civilised world" (Palmer, 1979, p.9). The fear of large common law suits being brought against them is one of the factors which, in other countries, leads employers to try to ensure that they have a safe working environment. It also leads them in some instances to provide funding for research into occupational health and safety hazards in order to avoid being faced, at some later date, with large claims for compensation from former workers. The recent attempts by asbestos companies in the United States to restructure as new corporate entities and thus avoid the massive law suits for cancer and other asbestos related diseases which will emerge in the future, reflects how seriously the corporations view the threat of such claims. The absence of any possibility of common law claims against employers in New Zealand brought about because of the Accident Compensation Act, means that there is no chance of any economic pressure to clean up the work place being brought to bear on employers through this avenue.

Apart from the question of the common law right to sue, levies for insurance cover are another method of attempting to regulate the number of accidents occurring in the workplace. Currently, the ACC levies companies at a rate which varies with the degree of danger involved in the occupational class being covered. The New Zealand levies tend to be lower than those paid overseas. This probably stems from the fact that in New Zealand the cost of hospitalisation is not paid for by levies to the ACC but out of general taxation, the bulk of which comes from wage and salary earners. Under the New Zealand scheme, employers also escape having to provide for product liability insurance as they cannot be sued for any injury resulting from the use of their products.

The Accident Compensation Act enables the ACC to increase levies on employers or to provide rebates to employers depending on whether their accident record is above or below average. The evidence from abroad seems to suggest that there may be some benefit in putting large penalties on companies with poor accident records. However, it also seems to indicate that rebates are largely ineffective. It is clear that, when rebates are provided, money does not go to employers which are the highest priority for the provision of resources; it goes to employers whose accident records are already significantly lower than average. It is also unlikely that the money which is distributed to firms under the rebate system is going to act as an incentive because it can only be relatively insignificant for most of the firms which receive it. The whole concept is as ineffective as one of distributing incentives to those who do not breach the traffic laws.

The current system of rebates needs to be abandoned because there is no evidence that it is effective. In its place a system of large additional levies on companies with bad accident rates should be introduced. This money should then be used by the ACC to provide resources to the unions involved in the company for occupational health and safety work and to ensure that the employer obtains information on hazards and takes the necessary steps to remove hazards which are creating the problem.

\section{Trade union involvement}

Because of its particular historical circumstances, the involvement of the New Zealand trade union movement in occupational health and safety issues has been sporadic. But some individuals within the union movement have placed great emphasis on this area of work and have attempted to bring about changes which would improve the working environment. Health and safety issues have been and continue to be the source of a large number of disputes throughout the country and recent years have seen an increasing recognition 

of the fact that trade unions have to be more closely involved in all aspects of the protec-
tion of the working environment.

The argument for increasing trade union involvement in occupational health and safety is firstly based on the belief that since it is the health and lives of workers which is at stake in industry, workers should be involved in decisions relating to the protection of the working environment. Secondly, it is likely that resources spent on providing information to workers will have a high return in terms of pressure for an improved working environment because they have an interest in protecting their own health and are always present on the shop floor where the hazards exist. The central mechanism for increased worker involvement in occupational health and safety is the concept of health and safety delegates or representatives. By providing resources to delegates specialising in health and safety a much closer monitoring of the work environment can be achieved. While a factory inspector may visit once every year or so, a delegate is present 8 hours a day 5 days a week. It is obvious that the development of such a health and safety delegate system is likely to be a cost effective method of increasing control of the standard of the work environment. There is already provision, in the Factories and Commercial Premises Act (s. 71), for regulations to be developed in regard to health and safety delegates and health and safety committees. It is to be hoped that the development of such regulations can commence in the near
future.

To provide a general overview of trade union activity in health and safety and to help initiate action, a trade union occupational health and safety project has been launched by the Federation of Labour with funding from the now disbanded Occupational Safety Trust Board. This project, also involving the Combined State Unions, will look at all the issues related to trade union involvement in occupational health and safety by developing a review report, holding a series of seminars in trades council districts and initiating action and safety matters. legislative and administrative ims to be considered by this project include proposals for the most effective areas for improvements, the provision of appropriate information, and time there have been a number of developments which reflect in safety. At the present in this area. These include health and safety delegates courses, the esed union activity health and safety resource unit in Auckland and the establishment of a in the area of occupational health and safety within the trade

\section{Summary}

This commentary has looked at those areas of the protection of the working environment where there is need for improvement. The working environment is not going to be made safe simply by good intentions. The most effective way of attacking the problem of workplace hazards is to ensure that there are economic sanctions against employers making the workplace hazardous; the provision of information and education to those who can use it in the field to protect the work environment; the integration and for regulatory agencies in relating to occupational health and safety; more resources ment in occupational health and there will be significant improvements in Until these measures are taken, it is unlikely that

\section{References} Department of Labour (1980) Report of the Department of Labour for the year ending
31 March 1980 Wellington, Government Printer.

Department of Labour (1982) Report of the Department of Labour for the year ending 
NZ problems and solutions

105

Palmer, G. (1979) Compensation for incapacity Wellington, Oxford University Press. Walker, I.K. (1981) Occupational safety : an inquiry into the coordination of legislation on industrial safety, health and welfare Wellington, State Services Commission. 